\title{
Influence of Replacement Time and Rate of Soybean Oil by Flax Oil in the Leghorn Hens' Diet on Polyunsaturated Fatty Acid Profile in Eggs
}

\author{
Nguyen Duy Hoan \\ Thai Nguyen University of Agriculture and Forestry, Thai Nguyen 25000, Vietnam
}

\begin{abstract}
The study was aimed to evaluate the effect of replacement time and rate of soybean oil by flax oil (FO) on polyunsaturated fatty acid (PUFA) profile in egg of laying hens. Two hundred White Leghorn hens with 30 weeks of age were divided into five treatments with four replicates of 10 birds each. Treatments were assigned randomly and consisted of $0.00 \%, 0.75 \%, 1.50 \%, 2.25 \%$ and $3.00 \%$ FO in commercial corn-soybean meal diets, in which the soybean oil was partially replaced. The experiment was conducted for $90 \mathrm{~d}$. The main research findings were that feed intake, egg production rate, egg weight and feed conversion were not influenced by time and dietary treatment. Fatty acid content was significantly altered $(P<0.05)$ by FO, showing a progressive increase in egg n-3 fatty acid (especially docosahexaenoic acids (DHA) and eicosapentaenoic acids (EPA)) when FO was added. Levels of EPA and DHA were higher $(P<0.05)$ in the egg lipids of FO fed hens than those in the control group. However, no significant differences were observed either in egg weight or egg production among groups. The highest incorporation $(P<0.05)$ of total $\mathrm{n}-3$ fatty acid content in eggs was obtained with $3 \% \mathrm{FO} / \mathrm{kg}$. This increase was proportional to FO inclusion levels in the diets.
\end{abstract}

Key words: Egg enriched, laying hens, n-3 and n-6 fatty acids, FO.

\section{Introduction}

The World Health Organization recommends that diets should provide less than $1 \%$ of total energy intake as trans fatty acids [1-3]. Traditionally, western diets are deficient in excessive amounts of $\omega-6$ polyunsaturated fatty acid (PUFA) [4]. In many countries, the consumption of oil products is low; hence the benefit which could be derived from a diet rich in n-3 PUFA, does not reach the majority of the population. Nishida and Uauy [5] and Simopoulos [6] reported that fatty acid (FA) content of the egg yolk can be modified through nutrition. Currently, flax oil (FO) and marine products are used commercially to achieve this effect. FO contains $48 \%$ to $58 \%$ of n- 3 fatty acids, and it has been indicated that an increase of flaxseed in laying hen diets by $1 \%$ would result in an increase in

Corresponding author: Nguyen Duy Hoan, Ph.D., associate professor, research field: animal husbandry. E-mail: ndhoan@1rc-tnu.edu.vn. n-3 fatty acid deposition by $40 \mathrm{mg} / \mathrm{egg}$ [7].

The Hmong at Vietnam resides at altitude from 800 $\mathrm{m}$ to $1,500 \mathrm{~m}$ above sea level, including most of the Northern mountainous province of a relatively large geographical areas, along the border of Vietnam-China and Vietnam-Laos from Lang Son to Nghe An, which mainly focuses in the provinces located in the North-West and North-East areas of Vietnam, such as Ha Giang, Lao Cai, Lai Chau, etc.. According to the census of population and housing in 2009 published by the General Statistics Office Vietnam [8], the Hmong in Vietnam has a population of $1,068,189$ people, ranking eighth in the list of ethnic groups in Vietnam. Hmong people have a long tradition of flax cultivation for self-woven fiber of their clothing. The area of flax is estimated 1,500 ha. Each year over 10 tons of flax seed is produced but not used. The aim of the present study was to evaluate the effect of FO supplemented on PUFA composition in eggs of Leghorn hens. 


\section{Materials and Methods}

\subsection{Birds and Diets}

Experiments were arranged according to multivariate testing methods. Two hundred White Leghorn hens were divided into five treatments $(10$ hens/treatment) with four replicates. Experimental hens were fully vaccinated prescribed vaccines and housed in individual iron cages with density 0.15 $\mathrm{m}^{2} /$ hen. The age of the hens at the start of the experiment was 30 weeks and an average body weight was $1,848.24 \pm 80 \mathrm{~g}$. The treatments were assigned randomly and consisted of the incorporation of $0.75 \%$, $1.5 \%, 2.25 \%$ and $3 \%$ in substitution of identical amount of soya oil in commercial corn-soybean diets. The diets were calculated as shown in Table 1 to meet the recommendations of the Thai Nguyen University of Live-Science Institute, and the experiment lasted 90 d (three months production periods). Diets were formulated based on chemical analysis of metabolizable energy (ME), n-3 and n-6 fatty acid profiles in the soybean oil and FO used in this study (Table 2). Feed mixtures were made fresh just prior to each month production period. Feed and water were offered for ad libitum consumption. Data from feed intake, egg production, egg weight and feed conversion ratio were calculated and egg samples were collected over a month production period.

\subsection{Analytical Methods}

At days 28, 56 and 84 (1, 2 and 3 months, respectively) after the study started, 10 eggs from each replicate (40 eggs/group) were collected and stored at $4{ }^{\circ} \mathrm{C}$ for whole egg (yolk and albumen) chemical analysis. In this study, the lipid content was analyzed in whole eggs (yolk and albumen) as pools of 10 eggs per sample. Three replicate of each sample were processed according to the methods described by Folch

Table 1 Analysis and percentage composition of the experimental diets with different levels of flax oil (\%).

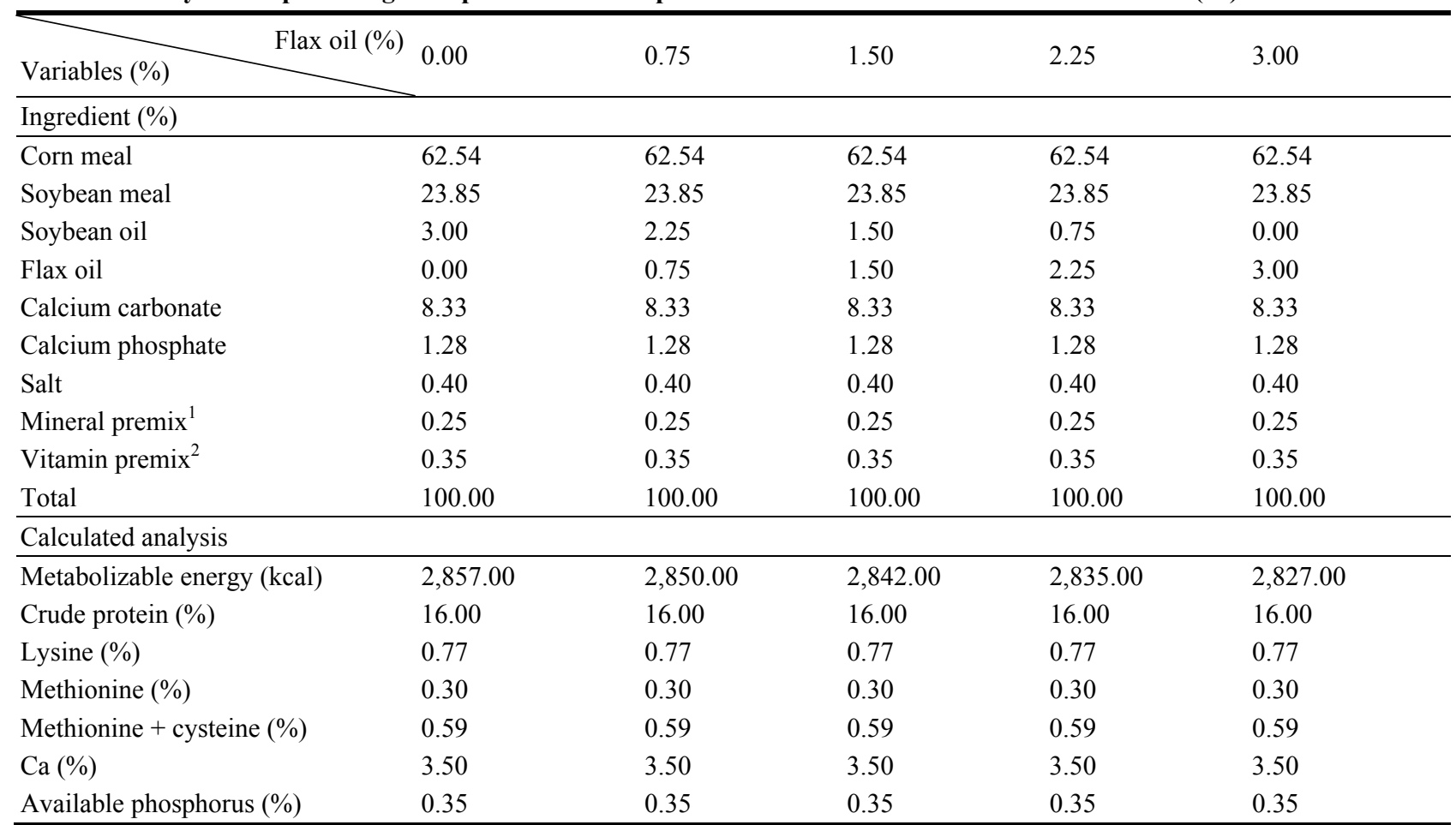

${ }^{\mathrm{T}}$ Vitamin premix supplied the following per kilogram of complete feed: vitamin A: 3,600 $\mu \mathrm{g}$; vitamin D3: $62.5 \mu \mathrm{g}$; vitamin E: 20.1 $\mathrm{mg}$; vitamin $\mathrm{K} 3: 2 \mathrm{mg}$; thiamine: $2.25 \mathrm{mg}$; riboflavin: $7.5 \mathrm{mg}$; pyridoxine: $3.5 \mathrm{mg}$; cobalamine: $0.02 \mathrm{mg}$; niacin: $45 \mathrm{mg}$; D-pantothenic acid: $12.5 \mathrm{mg}$; biotin: $0.125 \mathrm{mg}$; folic acid: $1.5 \mathrm{mg}$.

${ }^{2}$ Mineral premix supplied the following per kilogram of complete feed: zinc: $50 \mathrm{mg}$; copper: $12 \mathrm{mg}$; iodine: $0.3 \mathrm{mg}$; cobalt: $0.2 \mathrm{mg}$; iron: $100 \mathrm{mg}$; selenium: $0.1 \mathrm{mg}$. 
Table 2 Metabolizable energy (kcal/100 g) and PUFA composition of the soybean and flax oil used in the experimental diets (g/100 g).

\begin{tabular}{lll}
\hline Variables & Soybean oil & Flax oil \\
\hline ME & $889.43 \pm 12.02$ & $884.66 \pm 10.11$ \\
\hline Fatty acid composition & & \\
\hline ALA (C18:3) & $6.19 \pm 0.68$ & $44.03 \pm 2.32$ \\
EPA (C20:5) & $0.39 \pm 0.10$ & $0.69 \pm 0.10$ \\
DHA (C22:6) & $0.02 \pm 0.00$ & $0.27 \pm 0.10$ \\
DPA (C22:5) & $0.02 \pm 0.00$ & $0.09 \pm 0.00$ \\
LA (C18:2) & $48.97 \pm 2.12$ & $11.39 \pm 0.90$ \\
AA (C20:4) & $0.01 \pm 0.00$ & $0.17 \pm 0.00$ \\
\hline
\end{tabular}

Data is presented as mean \pm SE. ALA $=\alpha$-linolenic acid; EPA $=$ eicosapentaenoic acid; DHA $=$ docosahexaenoic acid; DPA $=$ docosapentaenoic acid; $\mathrm{LA}=$ linoleic acid; $\mathrm{AA}=$ arachidonic acid.

Table 3 Effect of the replacement rate of soybean oil by flax oil on feed intake, egg weight, egg production and feed conversion ratio of Leghorn laying hens.

\begin{tabular}{|c|c|c|c|c|c|}
\hline $\begin{array}{ll}\text { Variables } & \text { Flax oil (\%) } \\
\end{array}$ & 0.00 & 0.75 & 1.50 & 2.25 & 3.00 \\
\hline \multicolumn{6}{|l|}{ First month } \\
\hline Feed intake (g/day) & $102.00 \pm 2.00$ & $104.13 \pm 1.90$ & $104.12 \pm 1.80$ & $98.79 \pm 1.88$ & $99.34 \pm 1.23$ \\
\hline Egg weight (g) & $57.05 \pm 1.80$ & $56.63 \pm 0.81$ & $57.09 \pm 1.10$ & $58.24 \pm 0.98$ & $56.12 \pm 0.90$ \\
\hline Egg production (\%) & $92.84 \pm 1.50$ & $93.20 \pm 1.12$ & $91.80 \pm 0.90$ & $93.90 \pm 1.20$ & $91.30 \pm 0.80$ \\
\hline Feed conversion ratio $(\mathrm{kg} / \mathrm{kg})$ & $1.79 \pm 1.70$ & $1.86 \pm 0.60$ & $1.84 \pm 0.56$ & $1.75 \pm 0.65$ & $1.78 \pm 0.54$ \\
\hline \multicolumn{6}{|l|}{ Second month } \\
\hline Feed intake (g/day) & $108.00 \pm 1.61$ & $109.00 \pm 2.10$ & $111.20 \pm 1.98$ & $108.20 \pm 2.00$ & $108.30 \pm 1.87$ \\
\hline Egg weight (g) & $58.02 \pm 0.67$ & $58.12 \pm 1.00$ & $58.17 \pm 0.70$ & $59.23 \pm 0.70$ & $56.14 \pm 0.98$ \\
\hline Egg production $(\%)$ & $93.08 \pm 0.90$ & $93.03 \pm 1.10$ & $92.09 \pm 1.00$ & $93.07 \pm 0.90$ & $91.67 \pm 1.00$ \\
\hline Feed conversion ratio $(\mathrm{kg} / \mathrm{kg})$ & $1.87 \pm 0.20$ & $1.85 \pm 0.30$ & $1.92 \pm 0.40$ & $1.87 \pm 0.10$ & $1.90 \pm 0.40$ \\
\hline
\end{tabular}

Data is presented as mean \pm SE. In each column, there were no significant differences $(P>0.05)$.

et al. [9]. Methyl esters of fatty acids were obtained using boron trifluoride. Fatty acids were quantified by gas chromatography using a DB-23 column (JW $122-2332$ of $30 \mathrm{~m} \times 0.25 \mathrm{~mm}$ internal diameter) on a Varian $3400 \mathrm{CX}$ gas liquid chromatograph, equipped with an auto sampler and a flame ionization detector (Varian Associates, Inc., Sugar Land, TX). Nitrogen was the carrier gas at a flow rate of $30 \mathrm{~mL} / \mathrm{min}$. Temperatures were: column, $230{ }^{\circ} \mathrm{C}$; injector, $150{ }^{\circ} \mathrm{C}$; detector, $300{ }^{\circ} \mathrm{C}$. Myristic acid (Sigma Co., St. Louis, MO) was used as an internal standard for fatty acid. Retention times were compared with fatty acid methyl ester standards.

\subsection{Statistical Analysis}

Data from reproductive performance and PUFA content in the egg were evaluated by variance analysis using the general linear models (GLM) procedure. Significant differences $(P<0.05)$ were further separated with length of supply and replacement rate of soybean oil by FO as two effects using Duncan's multiple range test and statistical analysis system (SAS) 9.2 software [10]. Regression analysis between the inclusion of FO and n-3 fatty acid and n-6 fatty acid concentration in the egg content were submitted to analysis of variance (ANOVA; 2005).

\section{Results and Discussion}

\subsection{Reproduction Performance}

Results in Table 3 showed that the use of FO did not affect the reproduction performance of the Leghorn hen. Feed intake, egg weight, egg production and feed conversion ratio (FCR) of four treatments groups were equivalent with the control group after 
three months. It also showed that feed intake, egg weight, egg production and FCR were not affected by replacement rate of soybean oil by FO in the diet of the Leghorn hen. It is in agreement with Howe et al. [11] who incorporated different PUFA into hens' diets without finding any effect.

\subsection{Fatty Acid Composition}

Fatty acid composition of egg yolk is readily altered by dietary manipulation [12]. Results in Table 4 showed that fatty acid content was altered by FO inclusion with a progressive increase in egg n-3 PUFA, especially docosahexaenoic acid (DHA, C22:6) and eicosapentaenoic acid (EPA, C20:5) whit increasing levels. The increase was associated with a progressive decrease in $\alpha$-linolenic acid (ALA, C18:3), a precursor of the more biologically active forms of n-3, EPA and DHA. Levels of EPA were higher $(P<0.05)$ in the egg lipids of hens fed FO than those in the control group. Likewise, eggs from hens fed FO had higher DHA content than the control eggs. Means in each fatty acid per month with no common superscripts are different $(P<0.05)$. The results of analyzing the relationship between FO replacement rate in the diets and the incorporation of EPA into the egg yolk proved that there was a high correlation between the FO replacement rate in the diets and the incorporation of EPA $(r=0.96)(P<0.05)$ or DHA $(r$ $=0.92)$ into the egg yolk.

In the present study, a progressive decrease in linoleic acid (LA, C18:2) and arachidonic acid (AA, C20:4) was observed when FO was added (Table 5). The results of analyzing the relationship between FO replacement rate in the diets and the incorporation of LA into the egg yolk showed that there was a high correlation $(P<0.05)$ between the FO replacement in the diets and the incorporation of LA $(r=0.95)$ into the egg yolk. The highest incorporation of total n-3 fatty acid content in eggs was obtained with $3 \% \mathrm{FO}$ (Table 6). This increase was proportional to FO inclusion levels in the diets $(r=0.95)$.

Among the fatty acids, $n-3$ PUFA has been described

Table $4 \omega-3$ PUFA content (mg/100 g) of eggs from white Leghorn laying hens fed flax oil.

\begin{tabular}{|c|c|c|c|c|c|}
\hline $\begin{array}{l}\text { Flax oil (\%) } \\
\text { Variables }\end{array}$ & 0.00 & 0.75 & 1.50 & 2.25 & 3.00 \\
\hline \multicolumn{6}{|l|}{ EPA (C20:5) } \\
\hline Month 1 & $3.41 \pm 0.34^{\mathrm{e}}$ & $14.67 \pm 0.85^{\mathrm{d}}$ & $23.88 \pm 1.32^{\mathrm{c}}$ & $36.47 \pm 2.35^{\mathrm{b}}$ & $44.37 \pm 4.11^{\mathrm{a}}$ \\
\hline Month 2 & $3.80 \pm 0.23^{\mathrm{e}}$ & $15.34 \pm 1.94^{\mathrm{d}}$ & $23.32 \pm 1.67^{\mathrm{c}}$ & $34.67 \pm 2.15^{\mathrm{b}}$ & $53.22 \pm 4.34^{\mathrm{a}}$ \\
\hline Month 3 & $3.16 \pm 0.12^{\mathrm{e}}$ & $14.70 \pm 0.99^{\mathrm{d}}$ & $24.07 \pm 1.36^{\mathrm{c}}$ & $33.72 \pm 3.00^{\mathrm{b}}$ & $44.80 \pm 3.50^{\mathrm{a}}$ \\
\hline Average & $3.45 \pm 0.22^{\mathrm{e}}$ & $14.90 \pm 0.76^{\mathrm{d}}$ & $23.79 \pm 1.23^{\mathrm{c}}$ & $34.91 \pm 1.56^{\mathrm{b}}$ & $47.69 \pm 2.45^{\mathrm{a}}$ \\
\hline \multicolumn{6}{|l|}{ DPA (C22:5) } \\
\hline Month 1 & $73.50 \pm 5.40^{\mathrm{a}}$ & $19.00 \pm 2.90^{\mathrm{b}}$ & $8.19 \pm 1.30^{\mathrm{c}}$ & $15.45 \pm 2.30^{\mathrm{b}}$ & $20.49 \pm 1.40^{\mathrm{b}}$ \\
\hline Month 2 & $49.82 \pm 3.20^{\mathrm{a}}$ & $17.08 \pm 3.70^{\mathrm{b}}$ & $13.17 \pm 2.10^{\mathrm{b}}$ & $15.36 \pm 1.13^{\mathrm{b}}$ & $24.48 \pm 2.10^{\mathrm{b}}$ \\
\hline Month 3 & $60.40 \pm 1.90^{\mathrm{a}}$ & $14.52 \pm 3.10^{\mathrm{b}}$ & $13.75 \pm 1.90^{\mathrm{b}}$ & $15.08 \pm 1.60^{\mathrm{b}}$ & $23.23 \pm 1.60^{\mathrm{b}}$ \\
\hline Average & $61.24 \pm 3.80^{\mathrm{a}}$ & $16.87 \pm 1.80^{\mathrm{b}}$ & $11.52 \pm 1.10^{\mathrm{bc}}$ & $15.30 \pm 1.45^{\mathrm{b}}$ & $22.83 \pm 1.00^{\mathrm{b}}$ \\
\hline \multicolumn{6}{|l|}{ DHA (C22:6) } \\
\hline Month 1 & $129.86 \pm 6.20^{c}$ & $341.43 \pm 22.30^{\mathrm{b}}$ & $366.81 \pm 28.90^{\mathrm{b}}$ & $501.74 \pm 31.20^{\mathrm{a}}$ & $520.94 \pm 34.50^{\mathrm{a}}$ \\
\hline Month 2 & $115.74 \pm 8.50^{\mathrm{d}}$ & $355.93 \pm 45.20^{\mathrm{c}}$ & $480.56 \pm 33.20^{\mathrm{b}}$ & $452.02 \pm 38.70^{\mathrm{b}}$ & $639.16 \pm 46.60^{\mathrm{a}}$ \\
\hline Month 3 & $127.50 \pm 6.70^{\mathrm{d}}$ & $318.79 \pm 32.80^{\mathrm{c}}$ & $425.77 \pm 27.00^{\mathrm{b}}$ & $461.20 \pm 38.80^{\mathrm{b}}$ & $604.35 \pm 42.30^{\mathrm{a}}$ \\
\hline Average & $124.36 \pm 4.30^{\mathrm{d}}$ & $338.72 \pm 20.50^{\mathrm{c}}$ & $419.50 \pm 19.90^{\mathrm{b}}$ & $470.38 \pm 22.60^{\mathrm{b}}$ & $591.18 \pm 35.40^{\mathrm{a}}$ \\
\hline \multicolumn{6}{|l|}{ ALA (C18:3) } \\
\hline Month 1 & $136.94 \pm 8.80^{\mathrm{ab}}$ & $153.12 \pm 8.70^{\mathrm{a}}$ & $110.28 \pm 9.60^{\mathrm{b}}$ & $98.54 \pm 6.20^{\mathrm{bc}}$ & $74.34 \pm 4.70^{\mathrm{cd}}$ \\
\hline Month 2 & $149.41 \pm 6.80^{\mathrm{a}}$ & $127.57 \pm 12.40^{\mathrm{b}}$ & $125.47 \pm 10.10^{\mathrm{b}}$ & $98.65 \pm 6.10^{c}$ & $83.93 \pm 6.00^{\mathrm{c}}$ \\
\hline Month 3 & $138.99 \pm 5.70^{\mathrm{a}}$ & $113.11 \pm 10.10^{\mathrm{b}}$ & $117.36 \pm 7.30^{\mathrm{b}}$ & $86.82 \pm 6.30^{\mathrm{c}}$ & $84.39 \pm 5.60^{c}$ \\
\hline Average & $141.78 \pm 4.60^{\mathrm{a}}$ & $131.26 \pm 8.70^{\mathrm{ab}}$ & $117.04 \pm 5.80^{\mathrm{b}}$ & $94.67 \pm 4.60^{c}$ & $81.13 \pm 3.50^{\mathrm{c}}$ \\
\hline
\end{tabular}

Data presented as mean \pm SE. ${ }^{a-e}$ Means with unlike superscripts differ significantly $(P<0.05)$. EPA $=$ eicosapentaenoic acid; DPA $=$ docosapentaenoic acid; DHA $=$ docosahexaenoic acid; ALA $=\alpha$-linolenic acid. 
Table 5 o-6 PUFA content (mg/100 g) of eggs from hens fed flax oil.

\begin{tabular}{|c|c|c|c|c|c|}
\hline $\begin{array}{l}\text { Flax oil (\%) } \\
\text { Variables }\end{array}$ & 0.00 & 0.75 & 1.50 & 2.25 & 3.00 \\
\hline \multicolumn{6}{|l|}{ LA (C18:2) } \\
\hline Month 1 & $1,833.38 \pm 121.40^{\mathrm{ab}}$ & $2,099.13 \pm 132.20^{\mathrm{a}}$ & $1,560.60 \pm 102.20^{b}$ & $1,346.30 \pm 76.10^{\mathrm{cd}}$ & $1,030.40 \pm 56.70^{\mathrm{d}}$ \\
\hline Month 2 & $1,891.48 \pm 89.00^{\mathrm{a}}$ & $1,859.99 \pm 268.20^{\mathrm{a}}$ & $1,853.99 \pm 123.00^{b}$ & $1,391.10 \pm 74.20^{b}$ & $1,180.70 \pm 67.20^{b}$ \\
\hline Month 3 & $1,851.73 \pm 85.60^{\mathrm{a}}$ & $1,567.73 \pm 130.00^{\mathrm{a}}$ & $1,480.83 \pm 98.50^{b}$ & $1,215.40 \pm 90.00^{c}$ & $1,200.50 \pm 76.40^{c}$ \\
\hline Average & $1,860.20 \pm 66.70^{\mathrm{a}}$ & $1,842.28 \pm 119.10^{\mathrm{a}}$ & $1,617.07 \pm 68.60^{\mathrm{b}}$ & $1,318.60 \pm 46.80^{\mathrm{bc}}$ & $1,141.10 \pm 40.80^{\mathrm{c}}$ \\
\hline \multicolumn{6}{|l|}{$\mathrm{AA}(\mathrm{C} 20: 4)$} \\
\hline Month 1 & $304.03 \pm 21.10^{\mathrm{a}}$ & $244.52 \pm 19.20^{\mathrm{a}}$ & $154.59 \pm 7.40^{\mathrm{b}}$ & $131.89 \pm 5.80^{b}$ & $106.42 \pm 9.30^{b}$ \\
\hline Month 2 & $318.77 \pm 16.90^{\mathrm{a}}$ & $224.46 \pm 32.20^{\mathrm{a}}$ & $199.33 \pm 9.50^{\mathrm{b}}$ & $134.51 \pm 6.60^{\mathrm{c}}$ & $122.81 \pm 8.20^{\mathrm{c}}$ \\
\hline Month 3 & $300.29 \pm 15.60^{\mathrm{a}}$ & $204.95 \pm 19.80^{\mathrm{b}}$ & $159.81 \pm 9.60^{\mathrm{b}}$ & $114.13 \pm 9.10^{c}$ & $118.71 \pm 8.10^{\mathrm{c}}$ \\
\hline Average & $330.83 \pm 10.40^{\mathrm{a}}$ & $224.64 \pm 14.70^{b}$ & $169.16 \pm 6.00^{c}$ & $126.91 \pm 22.30^{\mathrm{d}}$ & $116.40 \pm 5.00^{\mathrm{d}}$ \\
\hline
\end{tabular}

Data presented as mean \pm SE. ${ }^{\text {a-d }}$ Means with unlike superscripts differ significantly $(P<0.05)$. LA $=$ linoleic acid; AA $=$ arachidonic acid.

Table 6 Total n-3 and n-6 PUFA content (mg/100 g) of eggs from White Leghorn laying hens fed flax oil.

\begin{tabular}{|c|c|c|c|c|c|}
\hline $\begin{array}{l}\text { Flax oil (\%) } \\
\text { Variables }\end{array}$ & 0.00 & 0.75 & 1.50 & 2.25 & 3.00 \\
\hline \multicolumn{6}{|l|}{ n-3 PUFA } \\
\hline Month 1 & $343.71 \pm 19.20^{\mathrm{c}}$ & $528.20 \pm 36.20^{\mathrm{b}}$ & $524.56 \pm 38.90^{\mathrm{b}}$ & $652.20 \pm 39.00^{\mathrm{a}}$ & $660.16 \pm 47.20^{\mathrm{a}}$ \\
\hline Month 2 & $314.82 \pm 13.50^{\mathrm{d}}$ & $515.94 \pm 72.10^{\mathrm{c}}$ & $642.54 \pm 46.70^{\mathrm{b}}$ & $600.71 \pm 43.30^{\mathrm{b}}$ & $800.80 \pm 59.10^{\mathrm{a}}$ \\
\hline Month 3 & $332.07 \pm 11.90^{\mathrm{d}}$ & $461.12 \pm 46.80^{\mathrm{c}}$ & $580.95 \pm 37.80^{\mathrm{b}}$ & $596.83 \pm 37.50^{\mathrm{b}}$ & $756.79 \pm 53.00^{\mathrm{a}}$ \\
\hline Average & $331.24 \pm 19.70^{\mathrm{d}}$ & $501.77 \pm 30.80^{\mathrm{c}}$ & $577.60 \pm 71.00^{\mathrm{b}}$ & $615.27 \pm 24.60^{\mathrm{b}}$ & $742.80 \pm 31.80^{\mathrm{a}}$ \\
\hline \multicolumn{6}{|l|}{ n-6 PUFA } \\
\hline Month 1 & $2,141.40 \pm 144.00^{\mathrm{a}}$ & $2,343.65 \pm 156.80^{\mathrm{b}}$ & $1,715.20 \pm 112.10^{b}$ & $1,478.50 \pm 74.70^{b}$ & $1,136.90 \pm 66.20^{\mathrm{c}}$ \\
\hline Month 2 & $2,179.58 \pm 104.20^{\mathrm{a}}$ & $2,084.45 \pm 300.20^{\mathrm{b}}$ & $2,053.30 \pm 140.20^{\mathrm{a}}$ & $1,525.50 \pm 80.50^{\mathrm{b}}$ & $1,303.50 \pm 75.60^{c}$ \\
\hline Month 3 & $2,152.02 \pm 100.90^{\mathrm{a}}$ & $1,772.68 \pm 147.00^{\mathrm{ab}}$ & $1,640.65 \pm 99.90^{\mathrm{b}}$ & $1,329.50 \pm 100.00^{\mathrm{c}}$ & $1,319.20 \pm 86.40^{\mathrm{c}}$ \\
\hline Average & $2,157.67 \pm 68.70^{\mathrm{a}}$ & $2,066.93 \pm 133.30^{\mathrm{b}}$ & $1,786.24 \pm 76.50^{\mathrm{b}}$ & $1,445.75 \pm 52.40^{\mathrm{c}}$ & $1,257.50 \pm 45.60^{\mathrm{c}}$ \\
\hline
\end{tabular}

Data presented as mean \pm SE. ${ }^{\text {a-d }}$ Means with unlike superscripts differ significantly $(P<0.05)$.

to have the most effective immunomodulatory activities; and EPA and DHA from fish oil are more biologically potent than ALA [13]. Current western diets typically contains excessive amounts of n- 6 PUFA and high $\omega-6 / \omega-3$ ratio which have been associated with several pathological conditions, such as cardiovascular disease, cancer and inflammatory and autoimmune diseases, whereas increased levels of $\omega-3$ PUFA have been reported to reduce those conditions [14].

\section{Conclusions}

The results indicate that the use of FO for replacement soybean oil in the laying diet, up to a concentration of $3 \%$, did not have any detrimental effect on feed intake, egg weight, egg production and egg feed conversion ratio, while produce n-3 fatty acid enriched eggs.
The n-3 PUFA content in eggs can be increased by dietary supplementation with FO, and FO serves as n-3 fatty acids alternative feed ingredient in layer hen diets to produce a healthier choice of egg.

\section{References}

[1] Baucells, M. D., Crespo, N., Barroeta, A. C., LopezFerrer, S., and Grashorn, M. A. 2000. "Incorporation of Different Polyunsaturated Fatty Acids into Eggs.” Poultry Science 79 (1): 51-9.

[2] Burlingame, B., Nishida, C., Uauy, R., and Weisell, R. 2009. "Fats and Fatty Acids in Human Nutrition: Introduction." Annals of Nutrition Metabolism 55 (1-3): 5-7.

[3] Bourre, J. M. 2005. "Effect of Increasing the $\omega-3$ Fatty Acid in the Diets of Animals on the Animal Products Consumed by Humans." Medécine Sciences 21 (8-9): 773-9.

[4] Carrillo-Dominguez, S., Carranco-Jauregui, M. E., Castillo-Dominguez, R. M., Castro-Gonzalez, M. I., 


\section{Polyunsaturated Fatty Acid Profile in Eggs}

Avila-Gonzalez, E., and Perez-Gil, F. 2005. "Cholesterol and n-3 and n-6 Fatty Acid Content in Eggs from Laying Hens Fed with Red Crab Meal." Poultry Science 84 (1): 167-72.

[5] Nishida, C., and Uauy, R. 2009. "WHO Scientific Update on Health Consequences of Trans Fatty Acids: Introduction." European Journal of Clinical Nutrition 63: $1-4$.

[6] Simopoulos, A. P. 2009. Evolutionary Aspects of the Dietary $\omega-6: \omega-3$ Fatty Acid Ratio: Medical Implications." World Review of Nutrition and Dietetics 100: 1-21.

[7] Castro-Gónzalez, M. I., Montano-Benavides, S., and Pérez-Gil, R. F. 2001. "Fatty Acids in Sardine Canned in Tomato Sauce from Different Fishing Areas of the Mexican Pacific." Archivos Latinoamericanos de Nutrición 51 (4): 400-6.

[8] General Statistics Office of Vietnam. 2010, Statistical Yearbook 2009. Hanoi: Statistical Publisher, 166-8.

[9] Folch, J., Lees, M., and Sloane-Stanley, G. H. 1957. “A Simple Method for the Isolation and Purification of Total
Lipides from Animal Tissues." J. Bio. Chem. 226 (1): 497-509.

[10] Institute of SAS Inc. 2001. SAS User's Guide: Statistics. Cary, NC: SAS Institute Publisher, 88-104.

[11] Howe, P. R., Downing, J. A., Grenyer, B. F., and Bryden, W. L. 2002. "Tuna Fishmeal as a Source of DHA for n-3 PUFA Enrichment of Pork, Chicken and Eggs." Lipids 37 (11): 1067-76.

[12] Jia, W., Slominski, B. A., Guenter, W., Humphreys, A., and Jones, O. 2008. "The Effect of Enzyme Supplementation on Egg Production Parameters and $\omega-3$ Fatty Acid Deposition in Laying Hens Fed Flaxseed and Canola Seed." Poult. Sci. 87 (10): 2005-14.

[13] Vanek, C., and Connor, W. E. 2007. "Do n-3 Fatty Acids Prevent Osteoporosis?" American Journal of Clinical Nutrition 85 (3): 647-8.

[14] Marshall, A. C., Kubena, K. S., Hinton, K. R., Hargis, P. S., and Van Elswyk, M. E. 1994. "n-3 Fatty Acid Enriched Eggs: A Survey of Consumer Acceptability." Poult. Sci. 73 (8): 1334-40. 